\begin{tabular}{cc} 
UNIVERSITA \\
DEGLISTDI \\
DI TORINO \\
$\begin{array}{c}\text { ALMA UNIVRSIIAS } \\
\text { TAURINENSIS }\end{array}$ \\
& ECONOMICS AND STATISTICS \\
& WORKING PAPER SERIES \\
Founded in 1404 & Quaderni del Dipartimento di Scienze \\
Economico-Sociali e Matematico-Statistiche & ISSN 2279-7114 \\
\hline
\end{tabular}

\title{
BALANCING THE EQUITY-EFFICIENCY TRADE-OFF IN PERSONAL INCOME TAXATION: AN EVOLUTIONARY APPROACH
}

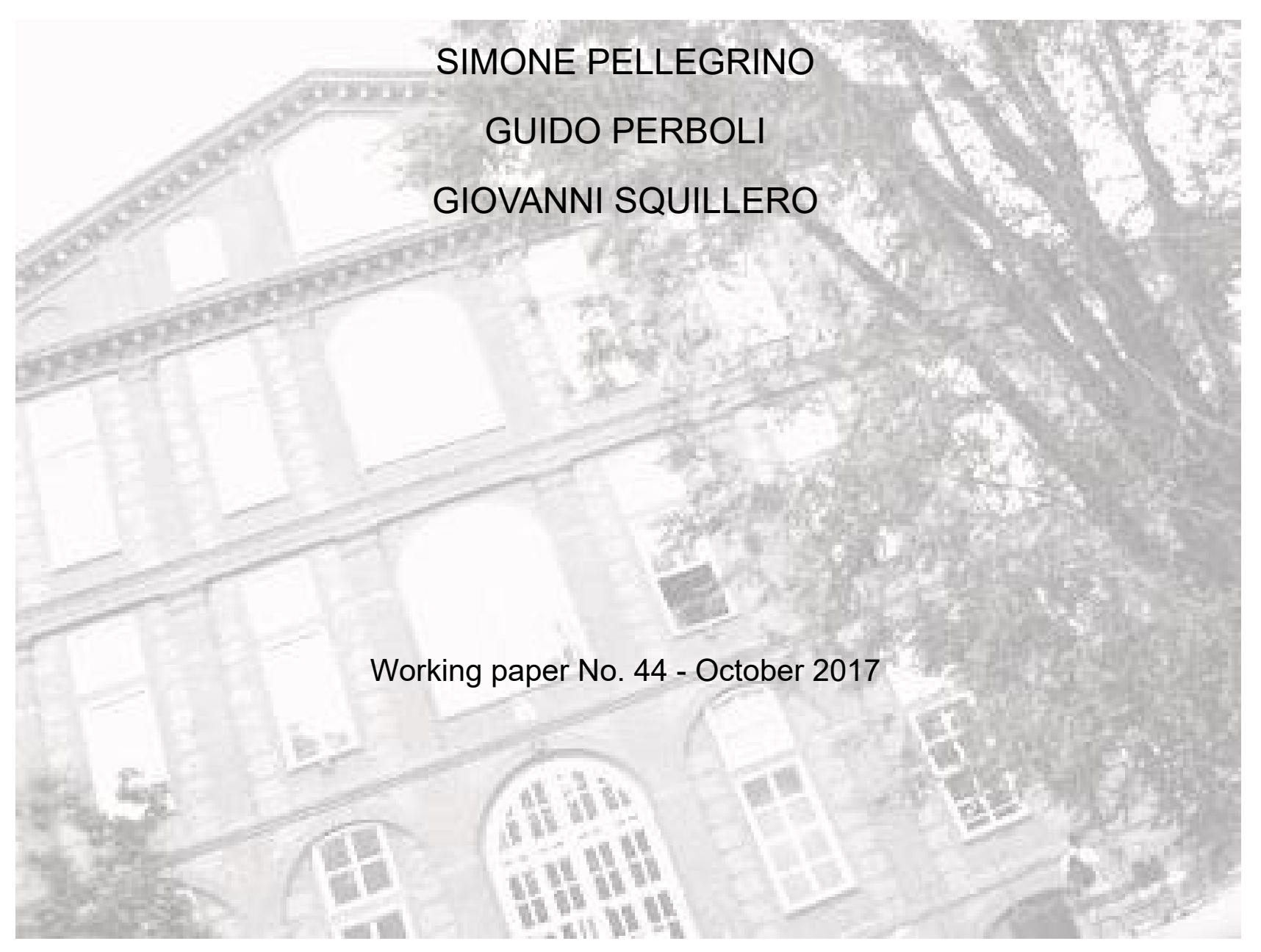




\title{
Balancing the Equity-efficiency Trade-off in Personal Income Taxation: An Evolutionary Approach
}

\author{
Simone Pellegrino ${ }^{\mathrm{a}}$, Guido Perboli $^{\mathrm{b}, \mathrm{c}}$, Giovanni Squillero $^{\mathrm{d}}$ \\ ${ }^{a}$ Department of Economics and Statistics - ESOMAS, University of Turin, Turin, Italy \\ ${ }^{b}$ ICT for City Logistics and Enterprises Center - Politecnico di Torino, Turin, Italy \\ ${ }^{c}$ CIRRELT, Montreal, Canada \\ ${ }^{d}$ Politecnico di Torino, Turin, Italy
}

\begin{abstract}
In this paper we propose a multi-objective evolutionary algorithm for supporting the definition of a personal income tax reform. As a case study, we apply this methodology to the Italian income tax, and consider a recently implemented tax cut. Our optimization algorithm is able to determine a set of tax structures that maximize the redistributive effect of the tax while minimizing its inefficiency - considering for the former the Reynolds-Smolensky index and for the latter the weighted average of taxpayers' effective marginal tax rates. The approach also takes into account two additional factors: the tax has to guarantee a specific revenue and to minimize the share of losing taxpayers with respect to the pre-reform situation. Experimental results clearly demonstrate that the methodology we employ can support the policy-maker's decisions in complex, realworld situations.
\end{abstract}

Keywords: Personal Income Tax, Evolutionary Algorithms, Multi-Objective Optimization

Email addresses: simone.pellegrino@unito.it (Simone Pellegrino), guido.perboli@polito.it (Guido Perboli), giovanni.squillero@polito.it (Giovanni Squillero) 


\section{Introduction}

One of the main issues regularly faced by any government in a real-world situation is if and how to consider and implement substantial tax reforms or a modification of some parameters of a specific tax $[1,2]$. In this work we focus on the personal income tax (PIT), that in all developed countries is the most important tax with respect to the total tax revenue as well as to its influence on economic efficiency and equity. PIT is also a perfect case study for a decision support system (DSS) problem, since its structure is generally very complex and characterized by dozens of parameters, such as marginal tax rates, upper limits of thresholds, several allowances and deductions, and tax credits.

Designing a PIT reform becomes a more and more complex task if the natural multi-objective nature of the problem is considered. To the classical revenue objective, other issues related both to social equity and efficiency of the newly designed systems should be adopted: the government can be interested in increasing the redistributive effect exerted by the tax system, but in so doing it can affect its efficiency. As for the redistributive effect in this paper we consider the Reynolds-Smolensky index $(R S)$ [3], while for efficiency we employ the weighted average of taxpayers' effective marginal tax rates (EMTRs).

We then try to solve these important issues when thinking of a tax reform. We got the idea by a recently tax cut implemented by the Italian government, that involved only one parameter of the tax; its goal was to increase the purchasing power of "poor" employees, as well as employees belonging to the "middle class" (a proxy for the redistributive effect maximization). This reform substantially increased both $R S$ and $E M T R s$, that is it improved equity and worsened efficiency (in addition to a remarkable worsening of the re-ranking effect) with respect to the situation observed before the tax reform.

Here we show that a set of other feasible tax structures, all reducing the tax revenue by the same amount, involving all the tax parameters and all taxpayers as well as better balancing equity and efficiency (and in the meanwhile keeping under control the re-ranking effect), are possible. Our methodology exploits an evolutionary algorithm, as such heuristics approaches have been demonstrated well suited to tackle complex real-world scenarios $[4,5,6]$. We then compare our results both with the effect of the reform recently implemented by the Italian government, and the one estimated in the article by Morini and Pellegrino [7], which is also based on an evolutionary algorithm framework.

In particular, fixing the tax revenue at the level observed after the government's tax reform, our evolutionary algorithm maximizes the redistributive effect and minimizes the inefficiency. Moreover, it also allows to satisfy an other fundamental factor: by considering the pre-reform tax structure, the computed set of admittable tax structures minimizes the share of losing taxpayers (in so doing we avoid the 
redistributive effect to increase only because the richest taxpayers are facing higher tax liabilities and increase the possibility that such a reform can be politically feasible). Among these results, the government can then choose the favorite one.

The paper is organized as follows. Section 2 focuses on the purposes of the paper by explaining its contribution to the existing literature. Section 3 describes the structure of the Italian PIT, and the reform implemented by the government. Section 4 shows equity and efficiency measures. Section 5 introduces the microsimulation model we employ for the empirical analysis and discusses the effects of the government tax reform on the equity and efficiency grounds. Section 6 describes TED (from the worlds "Tax", "Evolutionary", and "Decision"). Section 7 presents and discusses the results. Section 8 offers the conclusions.

\section{Problem Definition and State of the Art}

As stated in the introduction, our paper deals with a multi-facet problem of designing a DSS for supporting the decision makers in the complex process of reforming the PIT structure. The DSS is based on a multi-objective evolutionary algorithm and explicitly considers multiple objectives. Due to the very limited literature in DSS for PIT and the multidisciplinary nature of our research, we explore the related literature along two main axes: PIT policies and their evaluation, and multi-objective evolutionary algorithms.

\subsection{PIT Policies and their Evaluation}

Generally speaking, the degree of progressivity of a tax system observed in a country depends on several issues, such as the social preferences for redistribution, the level of inefficiency exerted by the overall tax system, the level of the total tax revenue desired by the community, and the composition of such total tax revenue, since it influences the economic growth. As a consequence, the optimal mix of these issues is country specific ${ }^{1}$.

\footnotetext{
${ }^{1}$ Some communities prefer higher degree of progressivity at the expense of efficiency; on the contrary, other communities prefer very low efficiency costs of taxation at the expense of the redistributive effect of the tax system. The some goes for the desired level (and composition) of the overall tax revenue (and consequently the desired level of the overall public spending): some countries have very high level of public spending and (consequently) tax revenue (e.g., Scandinavian countries), other have considerably lower values (e.g., US). Until the level of the public spending to be financed is low, efficiency costs of taxation are of little importance, and the greater concerns are focused on the possibility of obtaining the desired level of tax progressivity; on the other hand, when the level of public spending is high, efficiency costs of taxation become the key issue of the economic debate. Then "if society cares about inequality and poverty, there will always be some willingness to sacrifice a part of national income in order to achieve distributional objectives. The fundamental design issue is to minimize such losses while
} 
In this respect, economic literature has first identified the axioms to be required in order to equally apportion the burden of taxation among citizens $[9,10]$, with particular attention to the PIT structure on which we focus from now on: for a large set of utility functions the principles of equal sacrifice justify a progressive tax system. This fundamental result does not solve the problem of both how high the degree of progressivity and how high the level of the highest statutory marginal tax rate should be ${ }^{2}$.

For what concerns equity, the empirical studies evaluating the redistributive effect of the tax (or its improvements or deteriorations as a consequence of a tax reform) draw their conclusions from these redistributive indexes, such as the Reynolds-Smolensky index as well as the Kakwani and Atkinson-Plotnick-Kakwani ones [11]. In so doing, they stress the importance of the equity side of the problem, relegating to the background the efficiency side.

On the contrary, in the last decades the theoretical literature primarily concentrates on the equity-efficiency trade-off in optimum taxation following the methodology implemented by Mirrlees [12]. The results of this strand of the literature are not particularity useful for real-world tax policy design, since they employ stylized tax structure, and their solutions depend on the utility function considered; as a consequence, empirical works centre the attention on behavioral elasticities as the key parameters to draw conclusions on the efficiency costs of a tax or a tax reform [13].

One strand of the empirical literature focuses on the elasticity of labor supply with respect to the net wage. These studies find that this overall wage elasticity is very low, but it is decreasing with earned income: the wage elasticity is high for workers belonging to the bottom part of the income distribution and for married woman as well as older workers and it is very low for workers belonging to the top deciles of the income distribution $[14,15,8]$. From a policy recommendation point of view, these results are in favor of low marginal tax rates on poorer workers, and high marginal tax rates on richest ones, which in the meanwhile positively affect equity; this example underlines that the standard equity-efficiency trade-off can be not always verified $[15,16]$.

Another and more recent strand of the literature criticized some aspect of the results based on the elasticity of labour supply with respect to the net wage. In particular, this literature underlines that people reach to tax changes not only by

raising sufficient revenue to finance desired public services and satisfy concerns over inequality and poverty" [8].

${ }^{2}$ Today again the most important public economics textbooks discuss the ability-to-pay approach and the principles of equal sacrifice in the chapter regarding the theory of taxation, whilst they focus the attention on the the statistical and redistributive indexes when they handle with the evaluation of the effect of taxation on the income distribution. 
modifying their labour supply, but also by varying their effort, by reducing their tax compliance (i.e. by increasing tax evasion or by modifying taxable income by means of tax allowances and deductions). The parameter that can handle with all these possible responses to tax change is the elasticity of taxable income (ETI), which also allows to evaluate the dead-weight loss exerted by the PIT [17]. According to this strand of the literature, the estimated values of ETI vary across countries and years, and this elasticity seems to be particularly relevant for higher income individuals, whilst almost nil for lower income ones. The guideline of all this ETI literature underlines the efficiency concerns, whilst the redistributive ones are basically not taken into account.

Putting together, these two branches of the literature suggest focusing on the elasticity of labour supply when focusing on the bottom part of the income distribution, and on the elasticity of taxable income when considering top income earners [8].

It has to be noted that the economic literature primarily treats the problem of designing or re-designing the whole tax system or the whole structure of a specific tax, so that its conclusions are not sic et simpliciter applicable to a real-world situation, since governments have to balance other important short-run issues, such as the tax revenue to be collected and the political feasibility of the tax modification. As a consequence, "...there is no one-size-fits-all tax reform. Any tax reform must consider the institutions, the traditions, the economic policies, and especially the politics of the current and specific state situation. This means in particular that tax reforms must balance the various trade-offs that necessarily and inevitably exist between the need to generate revenues but to do so in an efficient and a fair way" [18]. In this respect, Morini and Pellegrino [7] underline that "... in order to implement a reform, the government usually changes some parameters of the tax compatible with its revenue constraint. Whether such a tax structure change is aimed at achieving the best way to obtain the specific target is debatable."

This paper tries to fit all these arguments by proposing a methodology for an equity-efficiency evaluation of real-world tax reforms, with a specific focus on the personal income tax; it can be particularly useful for helping policy-makers in setting a short-run PIT reform by balancing equity and efficiency concerns ${ }^{3}$.

\footnotetext{
${ }^{3} \mathrm{Up}$ to now examples in the literature of empirical strategies that both measure and balance the redistributive effect of the PIT and its inefficiency when considering real-world complex tax systems and the need for a government to implement a short-run tax reform are rare. Most of the results of the literature imply upheavals of the existing structure of the tax, hardly feasible at least in the short run. As a consequence, two partial evaluations are possible: given the structure of the PIT applied in a specific country and its redistributive effect, it is possible (under certain conditions) to measure the overall dead-weight loss exerted by the tax; on the contrary, forgetting
} 
In order to approach all these complex phenomena, we consider a recent tax cut implemented by the Italian government. In particular, the government decided to change one parameter of this tax in order to reduce the net tax liability only for a specific group of taxpayers. The result is an increase of the redistributive power of the tax at the expenses of both the average level of taxpayers' marginal tax rates (which we consider for the efficiency evaluation) and the re-ranking effect. By employing a multi-objective evolutionary algorithm, we are able to deal with most of the results of the above cited literature. In particular, our empirical strategy find a numerous set of equal-yield tax structures involving all the parameters of the tax and all the taxpayers; these tax reforms are all equally optimal for the problem under discussion, and depict several combinations of equity and efficiency.

In this our first attempt the dead-weight loss exerted by the tax on top income taxpayers is not explicitly considered, since here we discuss a tax reform reducing the tax revenue with no losing taxpayers with respect the situation observed before the tax reform; consequently, we can impose the highest statutory marginal tax rate to be lower or at most equal the present one without loss of generality; on the contrary, following the results of the literature on the wage elasticity, we ask the optimization core to balance the redistributive effect by lowering the effective marginal tax rates with a particular emphasis on the bottom part of the income distribution.

\subsection{Evolutionary Computation}

Evolution is the biological theory that animals and plants have their origin in other types, and that the distinguishable differences are due to modifications in successive generations. Natural evolution is based on random variations, but it is not a random process: variations are rejected or preserved according to objective evaluations, and only changes that are beneficial to the individuals are likely to spread into subsequent generations. Darwin called this principle "natural selection", a deterministic process where random variations simply "afford materials" [19].

Whether natural selection causes variations to be accumulated in one specific direction, the result may strikingly resemble a deliberate optimization process. However, such optimization processes only required to assess the effect of random changes and not the ability to design intelligent modifications. Several scholars and practitioners were inspired by such an outcome and tried to reproduce the process for solving practical optimization problems in various application domains, while others tried to mimic it to better understand its underlying mechanisms.

about the efficiency side, it is possible to evaluate its redistributive effect. If these effects are too high or too low, then it is possible to think about a possible tax reform, that inevitably would affect both the efficiency and the redistributive effect. 
Evolutionary Computation (EC) is the offshoot of computer science focusing on algorithms loosely inspired by the theory of evolution. The definition is deliberately vague since the boundaries of the field are not, and cannot be, sharply defined. EC is a branch of computational intelligence, and it is included into the broad framework of bio-inspired meta-heuristics.

EC does not have a single recognizable origin. Some scholars identify its starting point in 1950, when Alan Turing drew attention to the similarities between learning and evolution [20]. Others pointed out the inspiring ideas that appeared later in the decade, despite the fact that the lack of computational power impaired their diffusion in the broader scientific community [21]. More commonly, the birth of EC is set in the 1960s with the appearance of three independent research lines: John Holland's genetic algorithms; Lawrence Fogel's evolutionary programming; Ingo Rechenberg's and Hans-Paul Schwefel's evolution strategies. The three paradigms monopolized the field until the 1990s, when John Koza entered the arena with his genetic programming. Nowadays, all these methods, together with several variants proposed over the years, have been grouped under the umbrella term of evolutionary algorithms (EAs) [22].

When EAs are used to tackle a specific problem, an individual is a single candidate solution, and its fitness is a measure of its capacity of solving the problem; the set of all candidate solutions that exists at a particular time represents the population. Artificial evolution proceeds through discrete steps called generations. In each of them, the population is first expanded, and then collapsed, mimicking the processes of breeding and struggling for survival. The population in the first generation may be either completely random or seeded with existing solutions. Parents are chosen for breeding stochastically, with the best candidate solutions having higher probabilities to generate offspring. As a result, new candidate solutions are more likely to inherit favorable traits. Other considerations, such as age or diversity could also influence the selection probability, but generally to a smaller extent. Conversely, the removal of individuals is usually completely deterministic: the less fit, and possibly the oldest, are deleted.

The mechanisms used to generate the offspring are collectively named genetic operators. They can be divided into recombinations and mutations: the former methods mix together the information contained in two or more solutions to create new ones; the latter ones work by changing the structure of a single solution. Recombination operators are able to coalesce good characteristics from different solutions, and provide a very effective mechanism to explore the search space; mutation operators, on the other hand, allow the fine-tuning of the candidate solutions. Maintaining a set of solutions, EAs are resilient to the attraction of local optima. 
In many practical problems, the quality of the solution is defined in relation to several, conflicting, objectives. In most cases, it is not possible to define a single fitness function in order to direct the optimization process. Such a scalarization, a weighted aggregate function, may be unable to model intrinsically multi-objective scenarios.

Let say that a solution $A$ dominates a solution $B(A \succ B)$ if $A$ is not inferior to $B$ for all objectives, and it is strictly superior for at least one (Eq. 1). The goal of a multi-objective evolutionary algorithm (MOEA) is to provide a set of non-dominated solutions, and let the user eventually take the final decision. Such a set is called Pareto set (or Pareto front) after the XIX century Italian engineer and economist, who, indeed, originally used the concept in his studies of economic efficiency and income distribution.

$$
A \succ B \Longleftrightarrow \forall i: a_{i} \geq b_{i} \text { and } \exists j: a_{j}>b_{j}
$$

Nowadays, the de-facto standard for MOEA is Deb's NSGA-II [23], at least when the solution may be represented as a list of real parameters and the number of conflicting objectives is limited. However, this is a quite active research topic among scholars: the topic is of a great practical importance; tackling a multiobjective problem is significantly more difficult that optimizing a single function; and finding a Pareto front may not be sufficient, as the user is also expecting solutions to be quite different.

\section{Case Study: the Italian PIT}

\subsection{The Structure of the 2014 Italian PIT}

The 2014 Italian PIT is characterized by about three dozens of parameters that define its structure. In this Section we present these parameters by describing all the relevant rules for the transition from the pre- to the post-tax income. Unless otherwise stated, in this Section numerical values are expressed in euro.

Let $x$ be the generic taxpayer's gross income. The corresponding taxable income $y$ is given by the difference between the gross income $x$ and three kinds of allowances, if this difference is positive; otherwise the taxable income $y$ is equal to zero. The three allowances are the deduction for the main residence cadastral income $d_{1}$, the sum of the deductions for social security contributions and the alimonies as well as donations $d_{2}$, and the deduction for the solidarity contribution $d_{3}=\beta(x-\kappa)$ due only by taxpayers with $x>\kappa$. The present tax code considers $\kappa=300,000$ and $\beta=0.03$. More precisely,

$$
y= \begin{cases}x-d_{1}-d_{2}-d_{3} & \text { if } d_{1}+d_{2}+d_{3}<x \\ 0 & \text { if } d_{1}+d_{2}+d_{3} \geq x\end{cases}
$$


A rate schedule $\Psi(y)$ is applied to the taxable income $y . \Psi(y)$ considers five statutory tax rates $t_{j}$ (they are $t_{1}=0.23, t_{2}=0.27, t_{3}=0.38, t_{4}=0.41, t_{5}=0.43$ ) and four upper (lower) limits $U L_{\rho}=L L_{\rho+1}$ of the thresholds (they are $U L_{1}=$ $15,000, U L_{2}=28,000, U L_{3}=55,000$, and $\left.U L_{4}=75,000\right)$. By applying $\Psi(y)$ to $y$ the gross tax liability $\lambda$ is derived. Finally, the net tax liability $\tau$ is equal to the gross tax liability $\lambda$ minus three groups of effective tax credits (plus $d_{3}$ for richest taxpayers), if this difference is positive; otherwise it is set equal to zero ${ }^{4}$.

In particular, $c_{1}$ is the overall tax credit for earned income, $c_{2}$ is the overall tax credit for dependent individuals within the household, and $c_{3}$ is the overall tax credit for items of expenditure. Only $c_{1}$ and $c_{2}$ depend on the pre-tax income ${ }^{5}$, whilst $c_{3}$ does not.

More formally, the net tax liability $\tau$ is evaluated as follows:

$$
\tau= \begin{cases}\lambda-c_{1}-c_{2}-c_{3} & \text { if } \lambda>c_{1}+c_{2}+c_{3} \\ 0 & \text { if } \lambda \leq c_{1}+c_{2}+c_{3}\end{cases}
$$

Having evaluated $\tau$, the net income $z$ is simply the difference between $x$ and $\tau$.

Now we can turn to a detailed description of each kind of effective tax credits, $c_{1}, c_{2}$ and $c_{3} . \quad c_{1}$ is the overall tax credit for earned income. It is the sum of four different effective tax credits according to the taxpayer's kind of income $c_{1}=$ $\sum_{r=1}^{4} c_{1}^{r}$ where $r=1$ refers to employees, $r=2$ refers to pensioners younger than $75, r=3$ to pensioners older than 75 , and $r=4$ to self-employed taxpayers; nonworking taxpayers have a nil tax credit for earned income. In the 2014 tax year these tax credits have similar but different structures.

In particular, $c_{1}^{1}$ is equal to

$$
c_{1}^{1}= \begin{cases}\Omega & \text { if } x_{d} \leq A \\ \left(\Omega-a_{1}\right)+a_{1} \frac{U L_{2}-x_{d}}{U L_{2}-A} & \text { if } A<x_{d} \leq U L_{2} \\ \left(\Omega-a_{1}\right) \frac{U L_{3}-x_{d}}{U L_{3}-U L_{2}} & \text { if } U L_{2}<x_{d} \leq U L_{3} \\ 0 & \text { if } x_{d}>U L_{3}\end{cases}
$$

\footnotetext{
${ }^{4}$ Our definition of $\tau$ does not consider regional and municipal surtaxes, since their inclusion does not affect our methodology.

${ }^{5}$ More precisely, they depend on $x_{d}=x-d_{1}$ if the main residence is not subject to the property tax (the vast majority of cases starting from the tax year 2012; in these cases the cadastral income is considered within the definition of $x$, but an allowance of the same value is allowed) and on $x$ if the main residence is subject to the property tax (in these cases the cadastral income is not included in the definition of $x$ ).
} 
whilst $c_{1}^{r}$ for $r=(2,3)$ is equal to

$$
c_{1}^{r}= \begin{cases}t_{1} m_{r} & \text { if } x_{d} \leq m_{r} \\ \left(t_{1} m_{r}-a_{r}\right)+a_{r} \frac{U L_{1}-x_{d}}{U L_{1}-m_{r}} & \text { if } m_{r}<x_{d} \leq U L_{1} \\ \left(t_{1} m_{r}-a_{r}\right) \frac{U L_{3}-x_{d}}{U L_{3}-U L_{1}} & \text { if } U L_{1}<x_{d} \leq U L_{3} \\ 0 & \text { if } x_{d}>U L_{3}\end{cases}
$$

and

$$
c_{1}^{4}= \begin{cases}t_{1} m_{4} & \text { if } x_{d} \leq m_{4} \\ \left(t_{1} m_{4}-a_{4}\right) \frac{U L_{3}-x_{d}}{U L_{3}-m_{4}} & \text { if } m_{4}<x_{d} \leq U L_{3} \\ 0 & \text { if } x_{d}>U L_{3}\end{cases}
$$

where $m_{2}=7,500, m_{3}=7,750, m_{4}=4,800$, whilst $A=8,000 \neq 8,145=m_{1}$ (note that $m_{r}$ is the level of $x_{d}$ below which the taxpayer has a nil $\tau$ ); $a_{1}=902$, $a_{2}=470, a_{3}=486, a_{4}=0$; finally, $\Omega=1,880 \neq 1,840=t_{1} m_{1}$.

$c_{2}$ is the overall effective tax credit for dependent individuals within the household. It is the sum of four different tax credits according to the kind of relationship with respect to the taxpayer:

$$
c_{2}=c_{2}^{H}+c_{2}^{H F}+c_{2}^{S}+c_{2}^{O}
$$

where $c_{2}^{H}$ is the overall tax credit for dependent children, $c_{2}^{H F}$ is the further tax credit for households with more than three children, $c_{2}^{S}$ is the tax credit for the dependent spouse, and $c_{2}^{O}$ is the tax credit for other dependent components.

Starting with $c_{2}^{H}$, it is equal to

$$
c_{2}^{H}= \begin{cases}c_{2}^{H p} \frac{q+(f-1) e-x_{d}}{q+(f-1) e} & \text { if } x_{d} \leq q+(f-1) e \\ 0 & \text { if } x_{d}>q+(f-1) e\end{cases}
$$

where $f=\sum_{l=1}^{4} f_{l}$ is the overall number of dependent children. Each of them can be categorized in four groups: $f_{1}$ is the number of dependent children older than 3 years if the dependent children within the household are 3 or less; $f_{2}$ is the number of dependent children younger than 3 years if the dependent children within the household are 3 or less; $f_{3}$ is the number of dependent children older than 3 years if the dependent children within the household are more than $3 ; f_{4}$ is the number of dependent children younger than 3 years if the dependent children within the household are more than 3. $q$ is equal to 95,000, whilst $e$ to 15,000 and $c_{2}^{H p}=\sum_{l=1}^{4} f_{l} c_{2}^{H p l}$. The present values for the potential tax credits are $c_{2}^{H p 1}=950$, $c_{2}^{H p 2}=1,150, c_{2}^{H p 3}=1,220$, and $c_{2}^{H p 4}=1,420$.

A further tax credit $c_{2}^{H F}=1,200$ is applied to households with more than three children, provided that $c_{2}^{H}>0$. Note that potential tax credits for dependent children can be split between spouses whenever both of them have a positive gross income $x$; alternately, they can be ascribed to the richest between the spouses. 
The effective tax credit for the spouse is

$$
c_{2}^{S}= \begin{cases}c_{2}^{S p}-u \frac{x_{d}}{U L_{1}} & \text { if } x_{d} \leq U L_{1} \\ c_{2}^{S p}-u & \text { if } U L_{1}<x_{d} \leq w \\ \left(c_{2}^{S p}-u\right) \frac{k-x_{d}}{k-w} & \text { if } w<x_{d} \leq k \\ 0 & \text { if } x_{d}>k\end{cases}
$$

and

$$
c_{2}^{O}= \begin{cases}c_{2}^{O p} \frac{k-x_{d}}{k} & \text { if } x_{d} \leq k \\ 0 & \text { if } x_{d}>k\end{cases}
$$

where $u$ is equal to $110, w$ to $40,000, k$ to $80,000, c_{2}^{S p}$ is equal to 800 , whilst $c_{2}^{O p}$ to $750^{6}$.

Tax credits for items of expenditure $c_{3}$ can be classified in several groups according to the percentage of the expense the tax law admits as a tax credit. There are expenses that allow a tax credit of $19 \%, 24 \%, 41 \%, 50 \%$ and $55 \%$, respectively. Here we consider only two groups: $19 \%$ and 50\%, as the remaining ones refer to a very small number of beneficiaries. The $19 \%$ tax credits (we label this variable expenditure $_{1}$ ) refer to about twenty different items of expenditure, such as expenses for health care, mortgage interests, etc.; $50 \%$ tax credits (expenditure ${ }_{2}$ ) are allowed for home restructuring-related expenses.

Finally, $c_{3}$ also includes the tax credit for tenants; it is 300 if the gross income $x$ is less than 15,494 (we label this variable tenants $s_{1}$ ); 150 if the gross income

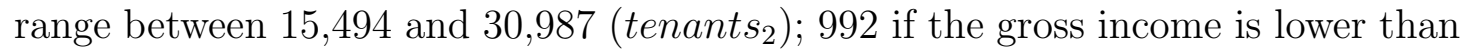
15,494 and the taxpayer is younger than 30 years $\left(\text { tenants }_{3}\right)^{7}$.

\subsection{The Government Tax Reform}

Without modifying the PIT structure, the government introduced a cash transfer

$$
\chi=\left\{\begin{array}{lll}
960 & \text { if } m_{1}<x \leq 24,000 & \& \lambda>c_{1} \\
960 \frac{26,000-x}{2,000} & \text { if } 24,000<x<26,000 & \& \lambda>c_{1} \\
0 & \text { if } x \geq 26,000 &
\end{array}\right.
$$

reserved for employees. As a consequence, taxpayers affected by $\chi$ evaluate $z$ as $y-\tau+\chi$, and those for whom $\tau<\chi$ receive a subsidy. As an example, Figure 1 shows the net effect $\tau-\chi$ for an employee without dependent individuals before and after the tax reform.

\footnotetext{
${ }^{6}$ For what concerns $c_{2}^{S}$, the formula applied by the Italian tax code is a little bit different. In particular, it considers higher values than $c_{2}^{S p}-u$ in the income range 29,000-35,200: instead of 690 , values range between 700 and 720 . We do not consider these differences in simulations, always letting $c_{2}^{S p}-u$ be equal to 690 .

${ }^{7}$ In simulations we do not consider specific thresholds to be applied for this tax credit, and we impose the above thresholds to be equal to $U L_{1}$ and $U L_{2}$, respectively.
} 
Figure 1: Net Tax Liability for an Employee

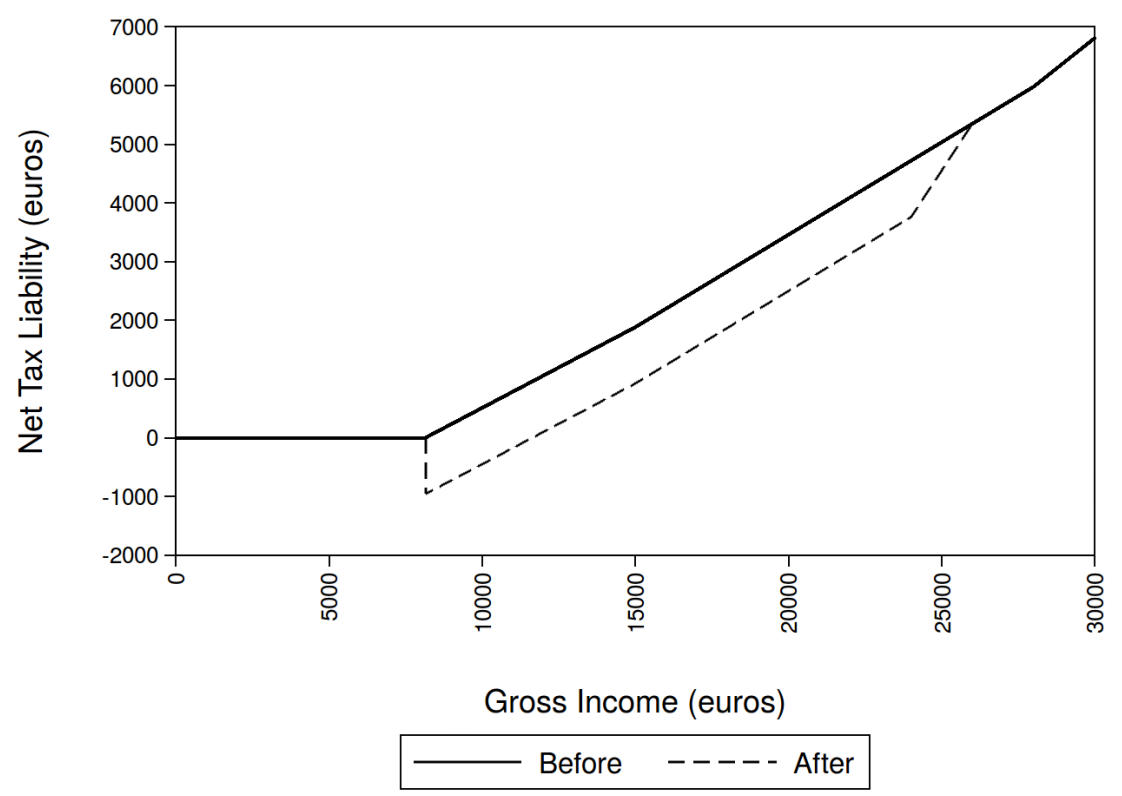

\section{Measuring Equity and Inefficiency: the Theory}

First of all the distribution of pre-tax incomes to which the PIT structure is applied has to be defined and formalized. We consider a vector of $N$ pre-tax incomes, $x_{1}, x_{2}, \ldots, x_{N-1}, x_{N}$, ranked in non-decreasing order. We call this distribution $X$. To each pre-tax income $x$ is associated a sample weight $\alpha_{1}, \alpha_{2}, \ldots, \alpha_{N-1}, \alpha_{N}$, where $\Upsilon=\sum_{n=1}^{N} \alpha_{n}$ is the overall number of taxpayers and $\bar{X}=\sum_{n=1}^{N} \alpha_{n} x_{n}$ is the overall amount of the gross income. To each $x_{n}$ is associated a corresponding value for the post-tax income $z_{n}$, as well as for the net tax liability $\tau_{n}$, so that $\bar{Z}=\sum_{n=1}^{N} \alpha_{n} z_{n}$ and $\bar{T}=\sum_{n=1}^{N} \alpha_{n} \tau_{n}$ are the overall amount of the net income and the overall amount of the tax revenue, respectively. We call these distributions $Z$ and $T$.

\subsection{Equity}

Inequality among income and tax levels can be measured according to a set of inequality measures. Here we employ the most famous among them, the Gini coefficient [24]:

$$
G_{\epsilon}=\frac{2 \cdot \operatorname{cov}(\epsilon, F(\epsilon))}{\mu_{\epsilon}}
$$

where $\epsilon=(X, Z, T), \mu_{\epsilon}$ is the average value of the considered distribution, cov represents the covariance, and $F(\epsilon)$ is the cumulative distribution function. 
Because of the tax, the post-tax as well as the tax liability ordering may differ with respect to the one observed before the $\operatorname{tax}^{8}$. To consider this phenomenon the concentration coefficients for the post-tax $C_{Z}$ and the tax liability distribution $C_{T}$ can be evaluated: they measure the inequality of these distributions once ordered according to the pre-tax order. More formally,

$$
C_{\epsilon}=\frac{2 \cdot \operatorname{cov}(\epsilon, F(X))}{\mu_{\epsilon}}
$$

where $G_{X}=C_{X}$ by definition and $G_{Z} \geq C_{Z}$ and $G_{T} \geq C_{T}$. A proportional tax leaves the post-tax as well as the tax liability inequality unchanged, so that $G_{X}=G_{Z}=G_{T}$ and no re-ranking can occur. If the tax is progressive, that is the average tax rate $\bar{\tau}_{n}=\frac{\tau_{n}}{x_{n}}$ is a non decreasing function of the pre-tax income, $T$ is distributed more unequally than $X$, and, conversely, $Z$ shows a lower degree of inequality [25]. The overall redistributive effect $R E$ can be measured by $R E=$ $G_{X}-G_{Z}=\left(G_{X}-C_{Z}\right)-\left(G_{Z}-C_{Z}\right)$ where $G_{X}-C_{Z}=R S$ is the ReynoldsSmolensky index, and $G_{Z}-C_{Z}=R_{A P K}$ is the Atkinson-Plotnick-Kakwani index, which measures the extension of the re-ranking occurred in the transition from the pre- to the post-tax incomes. Finally, the degree of tax progressivity is measured by the Kakwani index $K=C_{T}-G_{X}$. Note also that $R S$ and $K$ are linked by the overall average tax rate $\theta=\frac{\sum_{n=1}^{N} \tau_{n}}{\sum_{n=1}^{N} x_{n}}$ as follows $R S=\frac{\theta}{1-\theta} K$.

\subsection{Efficiency}

Having defined how to measure the progressivity of an income tax, we have to handle with the problem of measuring its inefficiency, that is a concept related to the structure of EMTRs. Generally speaking and by considering homogeneous taxpayers, if the tax is progressive, then $\tau_{n}^{\prime} \geq \bar{\tau}_{n}$ where

$$
\tau_{n}^{\prime}=\frac{\Delta \tau_{n}}{\Delta x_{n}}
$$

is the $E M T R$, which evaluates the increase of the taxpayer's net tax liability $\tau_{n}$ due to an increase in her pre-tax income $x_{n}$.

Besides statutory tax rates, real world tax systems allow tax credits that decrease the net amount each taxpayer has to pay; as described in Subsection 3.1,

\footnotetext{
${ }^{8}$ This means that after the tax some taxpayers may be poorer (their post-tax income $z$ is lower) than others even if their pre-tax income $x$ is greater; or some taxpayers may face a higher net tax liability $\tau$ even if their pre-tax income $x$ is lower.
} 
the Italian PIT considers a set of linearly decreasing ones ${ }^{9}$. In these cases, given an income $x$, the effective marginal tax rate $\tau^{\prime}$ is equal to the statutory tax rate $t_{j}$ plus the slope of each tax credit the taxpayer can benefit ${ }^{10}: \tau^{\prime}=t_{j}+\frac{\Delta c_{1}}{\Delta x}+\frac{\Delta c_{2}}{\Delta x}$.

Given the previous considerations, the trade-off between the redistributive effect and the structure of the effective marginal tax rates is clear. In order for both the overall redistributive effect $R E$ and the Reynolds-Smolensky index $R S$ to be the highest, the tax distribution should favor the poorest taxpayers and taxpayers belonging to the middle class, and disadvantage richest taxpayers. This can be obtained by three channels: (a) low statutory tax rates and (b) high slopes of the effective tax credits for the poorest taxpayers as well as (c) high statutory tax rates for richest taxpayers. By contrast, high statutory tax rates as well as high slopes of the effective tax credits imply higher effective marginal tax rates, that should be avoided on the efficiency point of view. We can handle with this problem by letting the $E A$ minimize the $E M T R$ weighted average value:

$$
I=\frac{1}{N} \sum_{n=1}^{N} \tau_{n}^{\prime} .
$$

Our problem then considers two constraints, one parameter to be maximized and one parameter to be minimized. Optimal solutions are tax structures that yield a specific tax revenue (this means the deviation of the computed tax revenue from the target one should be closest as possible to zero), and guarantee that the share of losing taxpayers (with respect to the situation observed before the tax reform) is the closest as possible to zero (this is very important, because we do not want $R S$ to increase only because the richer taxpayers face a higher net tax liability, given the tax cut). By considering these two constraints, admittable solutions balance all the possible combinations of $R S$ and $I$.

\footnotetext{
${ }^{9}$ If the tax system does not allow tax credits as well as allowances at all, the progressivity of the tax depends only on the rate schedule $\Psi(x)$; as a consequence, the statutory tax rates $t_{j}$ always correspond to the effective marginal tax rates $\tau_{n}^{\prime}$ for all income levels. If the tax system allows a constant tax credit for all taxpayers, then the statutory tax rates $t_{j}$ correspond to the effective marginal tax rates $\tau_{n}^{\prime}$ for all income levels, except for the income levels characterized by a nil net tax liability (the so called "no tax area").

${ }^{10} \mathrm{As}$ an example, consider an employee characterized by $x=10,000$, and $d_{1}=d_{2}=c_{2}=$ $c_{3}=0$. In this situation, $\lambda=2,300$, whilst $c_{1}=1,789.80$, so that $\tau=510.20$. Were the pre-tax income $x$ equal to 10,100 , the corresponding values would be: $\lambda=2,323, c_{1}=1,785.29$, $\tau=537.71$. Then the effective tax rate is $27.51 \%$. The statutory tax rate this taxpayer has to face is equal to $t_{j}=0.23$, whilst the derivative of $c_{1}$ with respect to $x$ is $\frac{\partial c_{1}}{\partial x}=-\frac{902}{20,000}=-0.0451$.
} 


\section{Measuring Equity and Efficiency: the Italian Case}

\subsection{The Data and the Micro-simulation Model}

As input data we make use of a static micro-simulation model developed by Simone Pellegrino about 10 years ago and constantly updated. It is written in STATA and is able to estimate the most important taxes and contributions which characterize the Italian fiscal system. Here we employ the micro-simulation model module concerning the PIT updated to the 2014 fiscal year. Technical details regarding the structure of previous versions of this microsimulation model and its applications to the analysis of the Italian PIT and the analysis of inequality indexes decompositions can be found in Pellegrino et al. [26], Morini and Pellegrino [7], Vernizzi and Pellegrino [27] and Monti et al. [28].

The micro-simulation model employs, as input data, those provided by the Bank of Italy [29] in its Survey on Household Income and Wealth (BI-SHIW), published in 2016 with regard to the 2014 fiscal year. The BI-SHIW survey contains information on household income and wealth of 8,156 households and 19,366 individuals. The sample is representative of the Italian population, composed of about 24.7 million households and 60.8 million individuals.

Considering individual taxpayers, results concerning the PIT gross income distribution, and the distribution of all tax variables as well as the overall tax revenue are very close to the Ministry of Finance's official statistics [30]. This instrument is then suitable for the type of empirical analysis we propose.

\subsection{The Effect of the Tax Reform Implemented by the Government}

Table 1 (column (a)) shows the inequality indexes, $I, \theta$ (x100) and $\bar{T}$ in the 2014 fiscal year before the tax reform. The Gini coefficient for the gross income distribution $G_{X}$ is 45.253 , whilst that for the net income distribution $G_{Z}$ is 40.249 . The overall redistributive effect $R E$ is 5.004 . The concentration coefficient for the net income distribution $C_{Z}$ is 40.161 , whilst that on the net tax liability distribution $C_{T}$ is 67.280 ; therefore, the Reynolds-Smolensky $R S$ index is equal to 5.092 and the Kakwani index $K$ is 22.027 . The overall average tax rate $\theta$ is $18.776 \%$, whilst the Atkinson-Plotnick-Kakwani index $R_{A P K}$ is equal to $0.088 ; I$ is equal to $24.600 \%$ and $\bar{T}$ to 151.685 billion euro.

Table 1 (column (b)) also presents the indexes after the tax reform implemented by the Italian government, which is our reference situation. The Gini coefficient for the net income distribution $G_{Z}$ is 39.810 , so that the overall redistributive effect $R E$ is 5.443. The concentration coefficient for the net income distribution $C_{Z}$ is 39.677, whilst that on the net tax liability distribution $C_{T}$ is 71.276 ; therefore, the Reynolds-Smolensky $R S$ index increases to 5.575 and the Kakwani index $K$ to 26.023 . The overall average tax rate $\theta$ decreases to $17.645 \%$ (and $\bar{T}$ to 142.545 
Table 1: Indexes for Taxpayers Before and After the Tax Reform

\begin{tabular}{lrc}
\hline Index & $\begin{array}{c}\text { Pre-reform } \\
\text { Value (a) }\end{array}$ & $\begin{array}{c}\text { Post-reform } \\
\text { Value (b) }\end{array}$ \\
\hline$G_{X}$ & 45.253 & 45.253 \\
$G_{Z}$ & 40.249 & 39.810 \\
$R E$ & 5.004 & 5.443 \\
$C_{Z}$ & 40.161 & 39.677 \\
$C_{T}$ & 67.280 & 71.276 \\
$R S$ & 5.092 & 5.575 \\
$K$ & 22.027 & 26.023 \\
$R_{A P K}$ & 0.088 & 0.133 \\
\hline$I$ & 24.600 & 25.834 \\
$\theta$ & 18.776 & 17.645 \\
$\bar{T}$ & 151.685 & 142.545 \\
\hline
\end{tabular}

billion euro), whilst the Atkinson-Plotnick-Kakwani index $R_{A P K}$ increases to 0.133 and $I$ to 25.834 .

Given the peculiarities (see Subsection 3.2) of the tax instrument applied by the Italian government, these results are not surprising: in particular, note that $R_{A P K}$ shows a branded deterioration; moreover, also $I$ increases because of the tax reform: taxpayers belonging to the 24-26 thousand euro class (about 1.3 million) are characterized by EMTRs equal to $80 \%$ (Figure 2), given the sharply slope of the cash transfer in this income range (see Eq. 11).

By considering a tax reduction of exactly the same amount, we show that an EA is able to obtain a set of possible solutions that simultaneously optimize both equity and efficiency, given the revenue and the no losing taxpayers constraints. Therefore these results are ameliorative and more balanced with respect the ones obtained by the Italian government.

In this first paper regarding taxes and MOEAs ${ }^{11}$, the 2014 Italian tax reform is a perfect case study; we prefer to consider a reform reducing the tax revenue

\footnotetext{
${ }^{11}$ To the best of our knowledge, the unique attempt to apply an evolutionary computation to taxation is the work by Morini and Pellegrino [7], which employs a mono-objective genetic algorithm for solving the same problem discussed in the present paper. This analysis primarily focuses on the tax redistribution side; the authors apply some constraints to the allowable parameters of the tax in order to avoid too imaginative solutions, but they do not take explicitly into account the relation between equity and efficiency. In particular, the authors get a solution which considerably enhances the redistributive effect as well as the level of the no tax area for all kinds of taxpayers at the expense of the level of the effective marginal tax rates, especially for taxpayers characterized by a pre-tax income slightly higher the "no tax area". The main limit of this cited work is the mono-objective nature of the solution approach, not sufficient to support the decision makers in the process of the design of a PIT system.
} 
Figure 2: EMTRs for an Employee

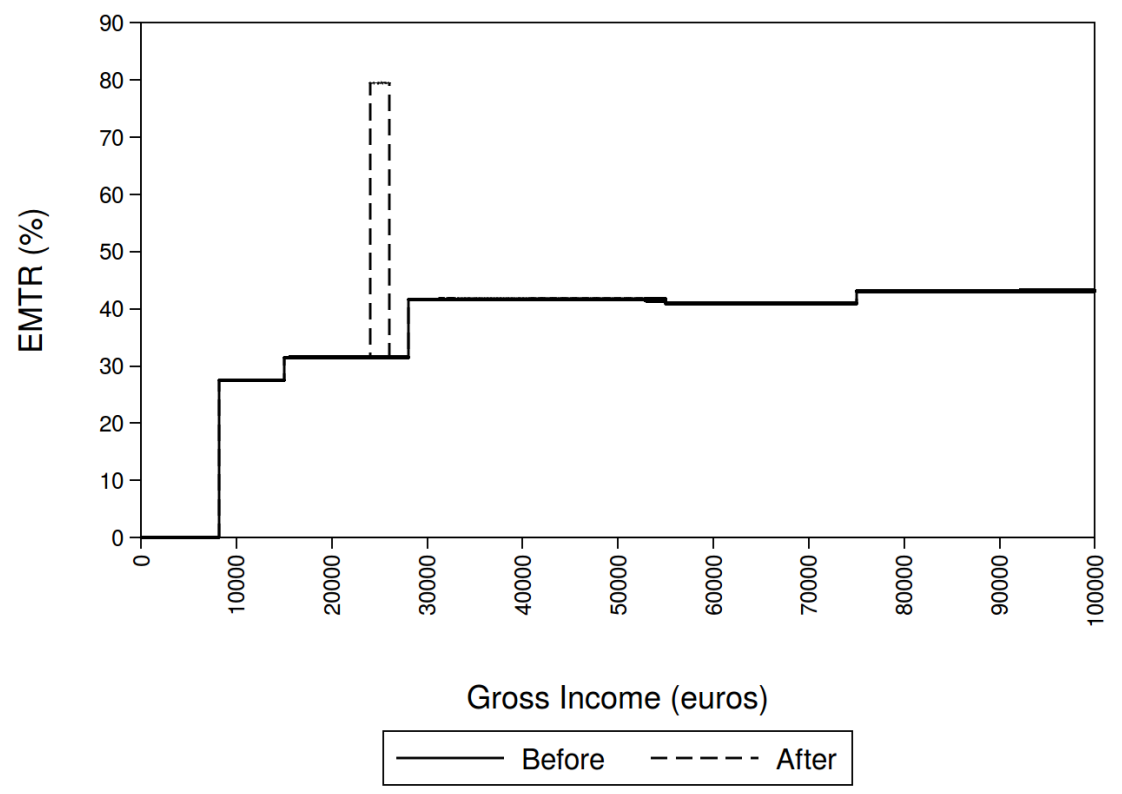

because in so doing we have not to handle with two kinds of discretionary choices: 1) the highest admittable statutory marginal tax rate can be set equal to the present top one (were the target tax revenue equal or higher than the present one, the highest admittable statutory marginal tax rate should be higher than the present one in order to obtain a feasible solution); 2) were the target tax revenue higher than the present one a positive share of losing taxpayers would be allowed; the choice of this share would be discretionary and results would depend on it. This does not mean that our empirical strategy cannot be employed to an equal-yield tax reform, but in this case choices 1) and 2) should be previously set; similarly for a tax reform enhancing the tax revenue.

\section{A Tax Evolutionary Decision Support System}

The goal of our DSS is to present the policy-maker a set of different, equally acceptable candidate solutions to choose from. We employ a multi-objective evolutionary algorithm to optimize the plausible goals of a PIT reform; the whole process is sketched in Algorithm 1. The final goal is to find multiple points on the Pareto front, each one corresponding to a different tax structure, optimal with respect to some specific goal. Indeed, the more diverse the Pareto front, the better. However, a standard MOEA cannot be directly exploited as the situation presents few peculiarities. 


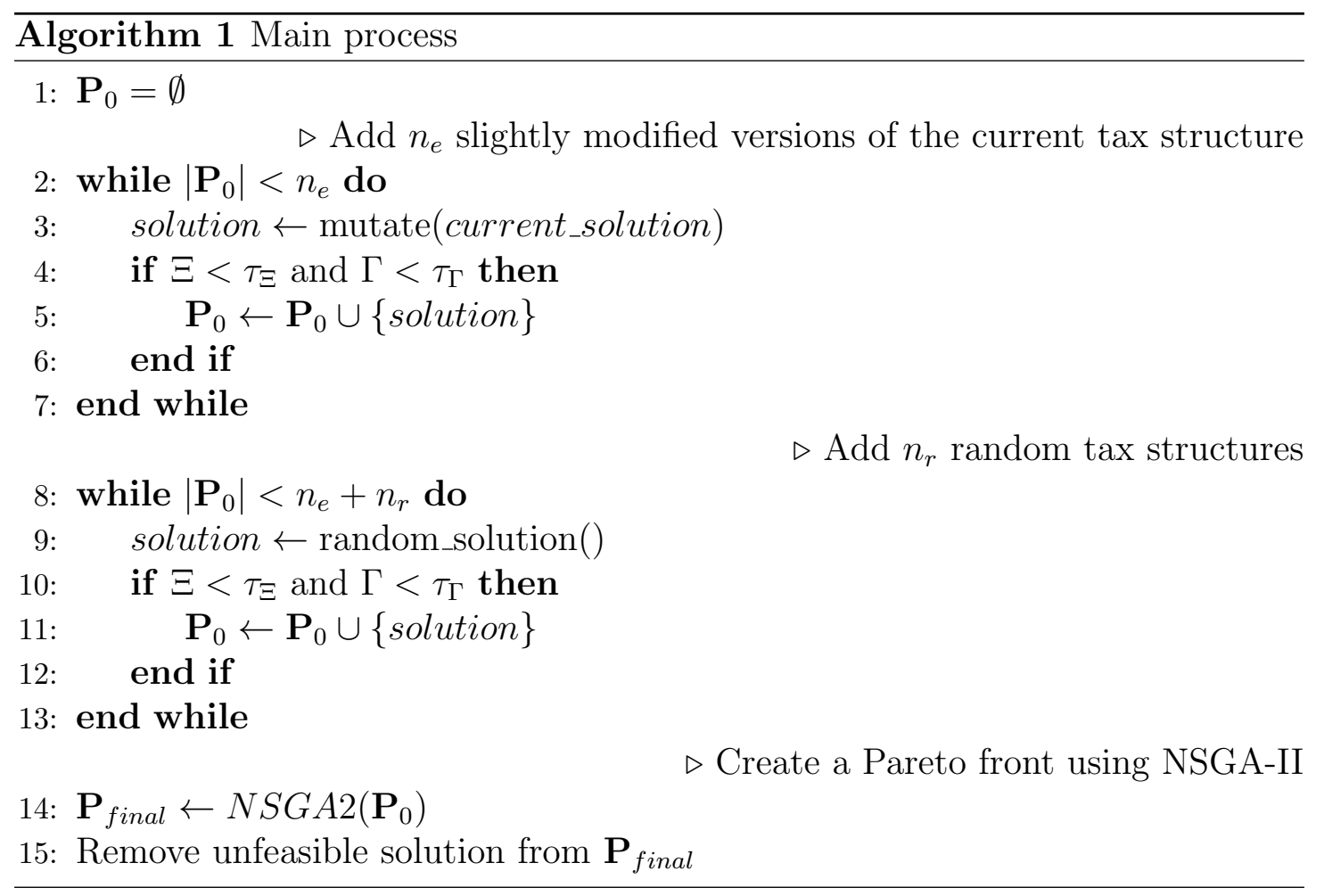

First, the structure of a PIT is rather complex, and the different parameters deeply interconnected. To broaden the applicability of the proposed solution, all tax structures are encoded as flat lists of real numbers, each one from zero to one $S=\left(l_{i}\right)$. With such a choice, the structure of a chromosome is simple and its validity is problem-independent; all individuals may be evaluated, as all chromosomes correspond to an acceptable tax structure; crossover operators may always be used; and, it allows the exploitation of established optimizers such as NSGA-II.

However, the performance of evolutionary algorithms increase significantly when the locality principle holds true, that is, when small changes in the genome cause small changes in the phenotype, and eventually small changes in the fitness [31]. The adopted encoding is likely to destroy the semantic of the parameters, invalidating the locality principle. For instance, a set of chromosomes is used for the statutory marginal tax rates, and each value encodes the normalized offset over the previous one; all possible values yield to a valid set of statutory marginal tax rates, but change on value is going to change the meaning of all successive ones.

Another problem arises from the fact that a reasonable PIT must guarantee that both the deviation of the computed tax revenue from the target one $(\Gamma)$ and the share of losing taxpayers $(\Xi)$ must be almost zero. First, a fuzzy concept like almost zero is difficult to be quantified as a formula. Moreover, imposing these hard 
constraints would result in a quite difficult problem with few acceptable solutions surrounded by vast infeasible region. Evolutionary algorithms are based on the concept of differential survival: two different solutions must be comparable, and one must yield an advantage over the other, even if almost imperceptible. Being able to choose between different alternatives is required by the selection process, but it is not possible to compare infeasible solutions.

To reduce the infeasible regions, instead of using a hard constraint, both the deviation from the target tax revenue $\Gamma$ and the share of losing taxpayers $\Xi$ have been included in generic penalty term: $\mathcal{P}=\Xi+\Gamma+\max (\Xi, \Gamma)$, that is, the sum of the two factors plus their infinity norm. The MOEA core was asked to minimize $\mathcal{P}$ as one of its objective, the structure of the penalty term suggests the evolutionary core to reduce both factors, giving priority to the one currently worse. The penalty term is used to create a small feasible region close to acceptable solutions $\left(\Xi<\tau_{\Xi}\right.$ and $\left.\Gamma<\tau_{\Gamma}\right)$, to allow the evolutionary core to optimize the structure. However, an excessive deviation or share of losers is unacceptable, and the fitness function is set to zero in such cases, discarding all individuals from the population.

As the feasible regions artificially created are small compared to the search space, a random initialization of the initial population is likely to be ineffective. Our approach requires a initialization procedure, where the search space is sampled either fully randomly or around the current PIT structure, in order to find a reasonable number of feasible solutions to start with.

As we don't know the value of the optimal solutions, the NSGA-II algorithm is run for a given amount of generations. Moreover, it has been slightly tweaked: the crossover operator is a blend crossover [32, 33]; the mutation is performed by applying a Gaussian mutation. Values outside the valid range $[0,1]$ are clipped.

\section{Application of the DSS to the Case Study}

\subsection{Chromosomes Definition}

In this section we present how we let the EA choose each chromosome $(c h r)$. In this respect, we follow the strategy described in the article by Morini and Pellegrino [7] since our application refers to an updated version of the same microsimulation model on the same country and on the same tax reform. As a consequence, we employ 36 chromosomes necessary to obtain the 33 parameters of the Italian PIT.

The first set of chromosomes (from 1 to 6 ) is used in order to define the value of the five statutory marginal tax rates $t_{j}$ as follows

$$
t_{j}=t_{\text {min }}+\sum_{\phi=1}^{j} \operatorname{ch} r_{\phi} \frac{t_{\max }-t_{\min }}{\sum_{\phi=1}^{6} c h r_{\phi}}
$$


for $j=(1,2,3,4,5)$ and $\phi=(1,2,3,4,5,6)$; we impose them to range between $10 \%\left(t_{\min }\right)$ and $43 \%\left(t_{\max }\right)$, and to comply with the condition $t_{j}<t_{j+1}$.

A second set of five chromosomes (from 7 to 11) defines the four upper limits $\left(U L_{\rho}\right)$ of the thresholds, being $U L_{\rho}<U L_{\rho+1}$, ranging between 15,000 $\left(U L_{\text {min }}\right)$ and 100,000 $\left(U L_{\max }\right)$. More precisely,

$$
U L_{\rho}=U L_{\text {min }}+\sum_{\phi=7}^{\rho} \operatorname{ch} r_{\phi} \frac{U L_{\text {max }}-U L_{\text {min }}}{\sum_{\phi=7}^{11} c h r_{\phi}}
$$

for $\rho=(1,2,3,4)$ and $\phi=(7,8,9,10,11)$.

We then employ seven chromosomes for the definition of $C_{1}^{r}$. In particular, 4 chromosomes $\phi=(12,13,14,15)$ describe the level of the no tax area $m_{r}$ with $r=(1,2,3,4)$ :

$$
\begin{gathered}
m_{1}=8,000+\operatorname{chr}_{12}\left(0.9 \cdot U L_{1}-8,000\right) \\
m_{2}=0.9375 \cdot m_{1}-0.2 \cdot c h r_{13} \cdot 0.9375 \cdot m_{1} \\
m_{3}=m_{2}+c h r_{14}\left(0.96875 \cdot m_{1}-m_{2}\right) \\
m_{4}=0.6 \cdot m_{1}-0.3 \cdot \operatorname{chr}_{15} \cdot m_{1}
\end{gathered}
$$

where 0.2 and 0.3 are arbitrarily chosen, whilst the other parameters are set according to the present tax structure in order to preserve the rank of $m_{r}$. In this respect, we do not consider the inequality $\Omega=1,880 \neq 1,840=t_{1} m_{1}$, and we let $t_{1} m_{1}$ be equal or greater than 1,840 instead of 1,880 . Finally, we employ three chromosomes $\phi=(16,17,18)$ in order to define parameters $a_{r}$ with $r=(1,2,3)$ in the range $0-t_{1} m_{r}$. In so doing, we chose all the relevant parameters defining the shape of the four effective tax credits for earned incomes (note that the present tax code sets $a_{4}$ equal to zero). We do not let these effective tax credits be piecewise decreasing with respect to limits others than those observed in the rate schedule. Were this tax credit decreasing with respect to other thresholds, the number and the level of effective marginal tax rates would not be under control: on the contrary, we want to minimize both the number and the level of all effective tax rates.

Turning to $c_{2}^{H}$, we let $c_{2}^{H p l}$ be chosen between $c_{2 \min }^{H p}=600$ and $c_{2 \max }^{H p}=5,000$, being the present values ranging between 950 and 1,420. We then employ five chromosomes $\phi=(19,20,21,22,23)$ to set the four tax credits for dependent children. In particular,

$$
c_{2}^{H p l}=c_{2 \min }^{H p}+\sum_{\phi=19}^{j} \operatorname{ch} r_{\phi} \frac{c_{2 \max }^{H p}-c_{2 \min }^{H p}}{\sum_{\phi=19}^{23} \operatorname{ch} r_{\phi}}
$$

Similarly to the present tax code, we impose the potential tax credit be higher for households with more than 3 children and lower for those with fewer than 3 
children, as well as higher for children aged 3 or less and lower for a child aged more than 3. We then add $c h r_{24}$ in order to set $q$ between 30,000 and 200,000 and $c h r_{25}$ in order to set $e$ between 0 and 75,000, being the present values equal to 95,000 and 15,000, respectively. Then $c h r_{26}$ sets $c_{2}^{H F}$ between zero and 2,000. Turning to $c_{2}^{S}$, we let $c_{2}^{S p}$ be chosen between 500 and 2,500 $\left(c h r_{27}\right)$, and we employ $c h r_{28}$ to set $u$ between zero and $c_{2}^{S p}$. Following the present structure of this tax credit, we allow $c_{2}^{S}$ to be piecewise linearly decreasing with respect to three thresholds: $0-U L_{1}, U L_{1}-w$ and $w-k$ where $U L_{2}<w<U L_{3}$ and $k>U L_{4}$ by introducing chromosomes $\phi=(29,30)$ :

$$
\begin{gathered}
w=U L_{1}+c h r_{29}\left(U L_{3}-U L_{1}\right) \\
k=w+c h r_{30}(150,000-w)
\end{gathered}
$$

We then define $c_{2}^{O}$ by letting $c_{2}^{O} p$ be chosen between $0.75 \cdot c_{2}^{H p 1}$ and $0.95 \cdot c_{2}^{H p 1}$ $\left(c h r_{\phi}=31\right)$, and letting this tax credit be linearly decreasing between zero and $k$, zero otherwise.

The last set of chromosomes $\phi=(32,33,34,35,36)$ defines the third kind of tax credits $c_{3}$. The tax credit for tenants considers

$$
\begin{gathered}
\text { tenant }_{1}=1,500 \cdot \text { chr }_{32} \\
\text { tenants }_{2}=\text { tenant }_{1} \cdot \text { ch }_{33} \\
\text { tenants }_{3}=\text { tenants }_{1}+\text { chr }_{34}\left(2 \cdot \text { tenant }_{1}\right)
\end{gathered}
$$

whilst chromosomes $\phi=(35,36)$ set the percentage of the expenses the tax law admits as further tax credits for items of expenditure. We let the EA choose both expenditure $_{1}$ and expenditure $e_{2}$ between $0 \%$ and 100\% (at present equal to $19 \%$ and $50 \%$, respectively.

\subsection{Results: Best Solutions and Pareto Front}

We ask the DSS to select an initial population of $n_{e}=1,000$ individuals, that is 1,000 different tax structures, each of them composed by 36 chromosomes defining the 33 PIT parameters. We set $\tau_{\Xi}=5 \%$ and $\tau_{\Gamma}=0.5 \%$, and let the EA evolve for 2,000 generations, and we get all the possible solutions that lie upon the Pareto Front. By considering our constraints, that is $R S, I$, the share of losing taxpayers $\Xi$ and the percentage deviation of the computed tax revenue of each run from the target one $\Gamma$, Table 2 shows some solutions we found on the Pareto front where $R S$ is greater than the pre-reform value (5.092), $I$ is lower than the pre-reform value $(24.600 \%)$. We rank these solution according to $R S$, in ascending order.

These solutions are all different and all equally optimal. Among these, the policy maker can then choose the preferred one. For example, the government 
might prefer a tax structure able to guarantee a low $I$ at the expense of $R S$. In this case it would choose the solution depicted in line 4 of Table 2 , in which $I$ is $21.0 \%$ and $R S$ is 5.231 ; note that this solution is not able to perfectly fit the target tax revenue (since $\Gamma$ is $0.4 \%$ ) and it causes $\Xi$ to be high (1.5\%). On the contrary, the government could prefer a solution with a high $R S$ at the expense of $I$; in this case it would choose the solution depicted in the last line of Table 2 , in which $\Gamma$ is $0.4 \%$ and $\Xi$ is $1.6 \%$.

In the next subsection we decide to explore in greater details the solution depicted in the bold line of Table 2, because this solution is able to perfectly fit the target tax revenue $(\Gamma=0)$ and to guarantee a very low $\Xi$. By contrast, with respect to the set of solutions presented in Table 2, this one guarantees values placed in mid-table for what concerns $R S$ and $I$.

Table 2: Solutions on the Pareto Front

\begin{tabular}{cccc}
\hline$R S$ & $\Gamma$ & $\Xi$ & $I$ \\
\hline 5.124 & 0.4 & 0.4 & 23.0 \\
5.144 & 0.3 & 1.3 & 23.3 \\
5.219 & 0.2 & 0.1 & 23.3 \\
5.231 & 0.4 & 1.5 & 21.0 \\
5.233 & 0.5 & 1.2 & 23.3 \\
5.263 & 0.2 & 0.9 & 23.6 \\
5.264 & 0.4 & 1.1 & 23.2 \\
5.306 & 0.5 & 1.3 & 23.0 \\
5.311 & 0.2 & 0.3 & 23.2 \\
5.318 & 0.3 & 0.3 & 23.2 \\
$\mathbf{5 . 3 4 2}$ & $\mathbf{0 . 0}$ & $\mathbf{0 . 4}$ & $\mathbf{2 3 . 3}$ \\
5.352 & 0.1 & 0.4 & 23.3 \\
5.355 & 0.4 & 0.3 & 23.2 \\
5.363 & 0.5 & 0.4 & 23.2 \\
5.378 & 0.3 & 0.5 & 23.3 \\
5.382 & 0.5 & 0.4 & 23.3 \\
5.426 & 0.4 & 1.6 & 23.6 \\
\hline
\end{tabular}

\subsection{Results: a Specific Tax Structure}

Table 3 shows pre- and post-reform PIT parameters according to the specific solution we decided to describe. In order to balance the highest admittable $R S$ and the lowest admittable $I$, the bottom marginal tax rate $t_{1}$ should considerably decrease from $23 \%$ to $16.16 \%$. This is a branded reduction, which lowers the gross tax liability not only for the poorest taxpayers but also for all the others. Given the revenue as well as the equity-efficiency constraints, the remaining statutory tax rates face changes of minor importance: $t_{2}$ increases by about $2 \%$ (from 27 to 29.01 ), whilst $t_{3}$ decreases by about $2 \%$ (from 38 to 36.17 ); $t_{4}$ decreases only a little 
(from 41 to $40.36 \%$ ), whilst, not surprisingly, the EA chose the highest admittable value for $t_{5}$, the present top marginal tax rate $(43 \%)$. For what concerns the bandwidth of the thresholds, the first two remain unchanged $\left(U L_{1}\right.$ is still 15,000, whilst $U L_{2}$ increases from 28,000 to 28,723 ), whilst the third and the fourth narrow ( $U L_{3}$ drops from 55,000 to $33,690, U L_{4}$ drops from 75,000 to 66,525 ) in order for the top one to widen.

In our multi-objective empirical strategy the "no tax area" enlarges for employees and pensioners (paramenters $m_{1}, m_{2}$ and $m_{3}$ ) only a little (about 400 euro), whilst it even shrinks by 13 euro (parameter $m_{4}$ ) for self-employed taxpayers. On the contrary, employing a mono-objective genetic algorithm, Morini and Pellegrino [7] find very wider values for the "no tax area" of all kind of taxpayers. Here the need of balancing the revenue constraint, the share of losing taxpayers as well as the maximization of $R S$ and the minimization of $I$ is particularly clear: the "no tax area" implies a zero EMTR, so that the wider the "no tax area" the easiest not only the reduction of $I$, but also the rise of $K$ and $R S$; however, the wider the "no tax area" the more the revenue constraint become relevant, and the more EMTRs should increase in order to comply with this constraint. Since $I$ has to be minimized, our EA does not enlarge too much the "no tax area" in order to reduce EMTRs also for taxpayers belonging to the "middle class" and to apply not remarkable reductions for richest taxpayers.

To properly understand these results, the distribution of taxpayers by income classes is crucial: in Italy about one third of taxpayers earns 10 thousand euro or less, about one third of taxpayers earn an income between 10 and 20 thousand euro, and a remaining third an higher income.

This overall result on the structure of EMTRs (that also depends on the other tax parameters that we will discuss below) can be summarized by looking to Figure 3, which shows the EMTRs for an employee without dependent individuals (similar results can be observed by considering other types of taxpayers).

To continue with the parameter list, the ones defining the shape of the effective tax credits for employees and pensioners younger than $75\left(a_{1}\right.$ and $\left.a_{2}\right)$ increase $\left(a_{1}\right.$ from 902 to 1,146, $a_{2}$ from 470 to 622 ), whilst $a_{3}$ (that refers to pensioners older than 75) shrinks a little (from 486 to 474); in these cases there is not a remarkable impact on the slope of these tax credits before and after the EA tax reform.

On the contrary, the shape of the tax credit for the spouse significantly change: $c_{2}^{S p}$ increases from 800 to 902 , whilst $u$ is set equal to zero, $w$ decreases from 40 thousand euro to a value just above $U L_{1}$ and $k$ suffers only a little decrease (from $80,000$ to 75,516$)$. Differently from the paper by Morini and Pellegrino [7], all the four $c_{2}^{H p l}$ potential tax credits for dependent children considerably increase; the increase is huge in particular for $c_{2}^{H p 4}$ and $c_{2}^{H F}$ : this is possible because these two tax credits benefit a small number of taxpayers. Note also that the slope 
Table 3: Present and Computed PIT Parameters

\begin{tabular}{|c|c|c|}
\hline Parameters & $\begin{array}{l}\text { Present } \\
\text { Value }\end{array}$ & $\begin{array}{l}\text { Computed } \\
\text { Value }\end{array}$ \\
\hline$t_{1}$ & 0.23 & 0.16157 \\
\hline$t_{2}$ & 0.27 & 0.29082 \\
\hline$t_{3}$ & 0.38 & 0.36169 \\
\hline$t_{4}$ & 0.41 & 0.40361 \\
\hline$t_{5}$ & 0.43 & 0.42999 \\
\hline$U L_{1}$ & 15,000 & $15,000.00000$ \\
\hline$U L_{2}$ & 28,000 & $28,723.41144$ \\
\hline$U L_{3}$ & 55,000 & $33,689.54860$ \\
\hline$U L_{4}$ & 75,000 & $66,525.28713$ \\
\hline$m_{1}$ & 8,145 & $8,579.37320$ \\
\hline$m_{2}$ & 7,500 & $7,952.20120$ \\
\hline$m_{3}$ & 7,750 & $8,279.83477$ \\
\hline$m_{4}$ & 4,800 & $4,787.04904$ \\
\hline$a_{1}$ & 902 & $1,146.11353$ \\
\hline$a_{2}$ & 470 & 622.37089 \\
\hline$a_{3}$ & 486 & 473.74773 \\
\hline$c_{2}^{S p}$ & 800 & 902.15935 \\
\hline$u$ & 110 & 0.00000 \\
\hline$w$ & 40,000 & $15,198.627880$ \\
\hline$k$ & 80,000 & $75,515.55867$ \\
\hline$c_{2}^{O p}$ & 750 & 822.15951 \\
\hline$c_{2}^{H p 1}$ & 950 & $1,060.90799$ \\
\hline$c_{2}^{\mathrm{H} p 2}$ & 1,150 & $1,379.61044$ \\
\hline$c_{2}^{H p 3}$ & 1,220 & $1,840.84226$ \\
\hline$c_{2}^{\widetilde{H} p 4}$ & 1,420 & $3,329.82064$ \\
\hline$q$ & 95,000 & $80,246.93436$ \\
\hline$e$ & 15,000 & $26,483.97576$ \\
\hline$c_{2}^{H F}$ & 1,200 & 1,901.60493 \\
\hline tenants $_{1}$ & 300 & 540.80588 \\
\hline tenants $_{2}$ & 150 & 170.43651 \\
\hline tenants $_{3}$ & 992 & $1,316.85310$ \\
\hline expenditure $_{1}$ & 0.19 & 0.16025 \\
\hline expenditure $_{2}$ & 0.50 & 0.40264 \\
\hline
\end{tabular}


Figure 3: EMTRs for an Employee

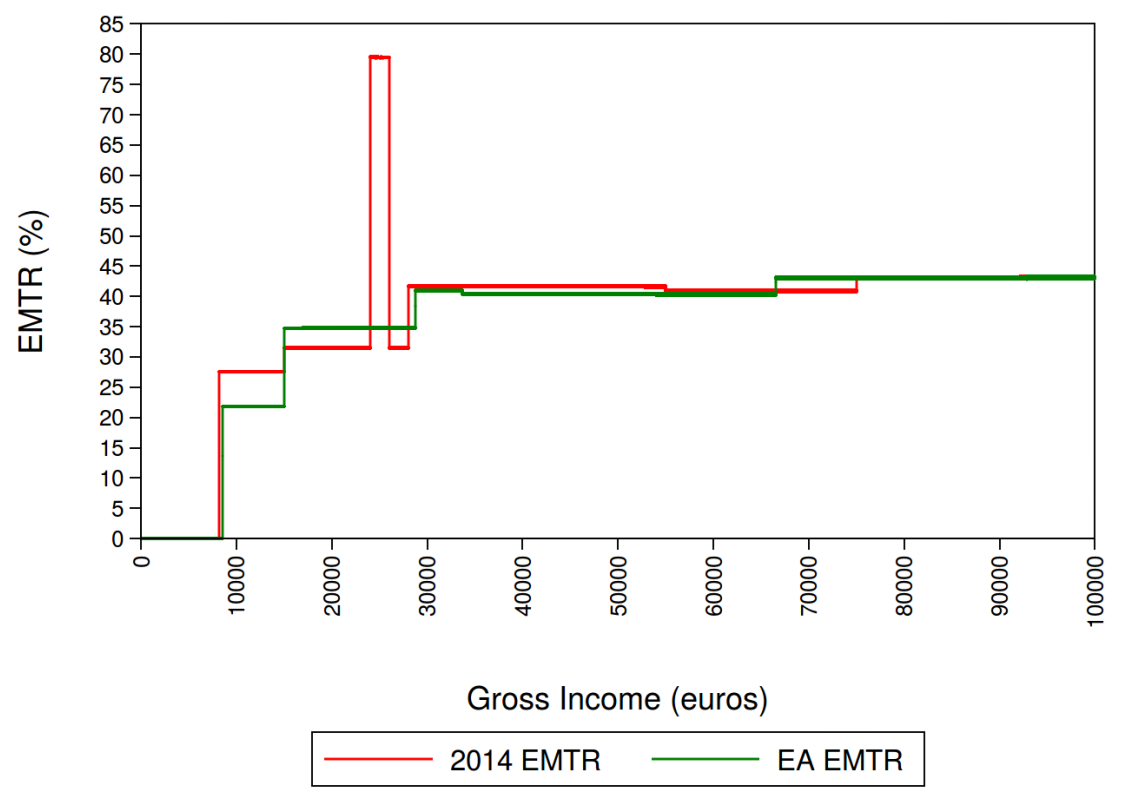

of $c_{2}^{H p l}$ (given by parameter $e$ ) decreases with $l$ (even if parameter $q$ decreases), and this positively affects $I$. Not surprisingly, parameters tenant $s_{1}$, tenant $s_{2}$ and tenants $_{3}$ increase: they contribute to raise $R S$ (because the tax credit for tenants particularly favors poorest taxpayers) with no effects on $I$, since they are constant in the income ranges they apply.

Finally, parameters expenditure ${ }_{1}$ and expenditure ex $_{2}$ decrease, the former from 19 to 16, and the latter from 50 to 40\%: tax credit for items of expenditure is enjoyed by taxpayers belonging to all income deciles and it does not depend on income, so that the increase of these parameters is not useful for both $R S$ and $I$ targets.

\subsection{A Closer Focus on the Results}

The MOEA reform reduces the tax revenue by 9.14 billion euro with respect to the tax structure applied before the tax reform. It is able to secure no losing taxpayers: only $0.42 \%$ (about 170 thousand income units) of the overall taxpayers loses, and on average they lose 108.6 euro; in particular, all these few losing taxpayers earn an income above 28 thousand euro and all poorer taxpayers do not lose. About $24 \%$ of taxpayers does not win and does not lose ${ }^{12}$, whilst the

\footnotetext{
${ }^{12}$ We consider as unaffected taxpayers for whom the difference between the net tax liability before and after the tax reform is less than one euro.
} 
remaining $75.6 \%$ wins, on average 302 euro. $54.31 \%$ of this tax cut accrues to taxpayers belonging the the 15-28 thousand euro class, whilst $22.66 \%$ to the ones of the 8-15 thousand euro class and $15.45 \%$ to the $28-55$ class (Table 4 ).

Table 4: The Composition of the Tax Cut

\begin{tabular}{lr}
\hline $\begin{array}{l}\text { Income Classes } \\
\text { (thousand euro) }\end{array}$ & $\begin{array}{c}\text { Composition } \\
\text { (\%) }\end{array}$ \\
\hline $0-8$ & 2.19 \\
$8-15$ & 22.66 \\
$15-28$ & 54.31 \\
$28-55$ & 15.45 \\
$55-75$ & 3.11 \\
above 75 & 2.27 \\
\hline Total & 100.00 \\
\hline
\end{tabular}

Given the multi-objective nature of our methodology, this composition is very different from the one obtained in the paper by Morini and Pellegrino [7], in which a very higher share on the 8-15 class and a very lower share on the 28-55 class is discussed: this is not possible in our framework because a higher share of the tax cut on the poorest taxpayers would negatively affect $I$. The two papers have in common the shares on the very rich and the very poor taxpayers. Only $2.19 \%$ of the tax cut favors the 0-8 income class; this may seem counterintuitive, but it has a technical explanation: in Italy the negative income taxation is not possible, so that taxpayers with a nil net tax liability cannot be affected by whatever tax reform. Finally, $5.4 \%$ of the tax cut favors taxpayers with incomes above 55 thousand euro: also this result is counterintuitive, but it depends on the complex tax structure characterized by three dozens of parameters; were the tax structure simpler, the EA would obtain a lower share also in this part of the income distribution.

We can finally discuss the effect of the EA tax reform on the inequality indexes (Table 5, column (c)).

The Gini coefficient for the net income distribution $G_{Z}$ is 40.002 , so that the overall redistributive effect $R E$ is 5.251 . The concentration coefficient for the net income distribution $C_{Z}$ is 39.911 , whilst that on the net tax liability distribution $C_{T}$ is 70.190; therefore, the Reynolds-Smolensky $R S$ index is then 5.342 and the Kakwani index $K$ is 24.937. The overall average tax rate $\theta$ is equal to $17.642 \%$, whilst the Atkinson-Plotnick-Kakwani index $R_{A P K}$ is $0.091 ; I$ is $23.342 \%$ and $\bar{T}$ is equal to 142.524 billion euro. Comparing $R S$ and $I$ as well as $R_{A P K}$ for the two tax reforms (Table 5, columns (b) and (c)), we can observe that all of them are lower when the EA reform is considered, as expected. The EA reform better balances $R S$ and $I$, that is it takes into account the trade-off between equity and efficiency: the first is obviously lower (5.342 instead of 5.575), and also the second is obviously 
Table 5: Inequality Indexes for Taxpayers: EA Results

\begin{tabular}{lrrr}
\hline Index & $\begin{array}{c}\text { Pre-reform } \\
\text { Value (a) }\end{array}$ & $\begin{array}{c}\text { Government } \\
\text { Value (b) }\end{array}$ & \multicolumn{1}{c}{$\begin{array}{c}\text { EA } \\
\text { Value (c) }\end{array}$} \\
\hline$G_{X}$ & 45.253 & 45.253 & 45.253 \\
$G_{Z}$ & 40.249 & 39.810 & 40.002 \\
$R E$ & 5.004 & 5.443 & 5.251 \\
$C_{Z}$ & 40.161 & 39.677 & 39.911 \\
$C_{T}$ & 67.280 & 71.276 & 70.190 \\
$R S$ & 5.092 & 5.575 & 5.342 \\
$K$ & 22.027 & 26.023 & 24.937 \\
$R_{A P K}$ & 0.088 & 0.133 & 0.091 \\
\hline$I$ & 24.600 & 25.834 & 23.342 \\
$\theta$ & 18.776 & 17.645 & 17.642 \\
$\bar{T}$ & 151.685 & 142.545 & 142.524 \\
\hline
\end{tabular}

lower (23.342\% instead of $25.834 \%$ ); since the government reform involves only one fourth of the taxpayers, whilst the EA one involves all of them, also $R_{A P K}$ is very lower (0.091 instead of 0.133) and close to that observed before the tax reform (Table 5, column (a)). Note that the EA reform also improves $R S$ and $I$ with respect the pre-reform situation, due to the difference in the tax revenue.

\section{Conclusions}

This paper shows how a multi-objective evolutionary algorithm can be a useful tool for helping policy-makers in setting a reform of the tax system. We consider a real-world tax reform involving the Italian personal income tax. In particular, the government decides to change one parameter of this tax in order to reduce the net tax liability only for a specific group of taxpayers.

The result is a decrease of the tax revenue by about 9 billion euro, an increase of the redistributive power of the tax at the expenses of both the average level of taxpayers' marginal tax rates and the re-ranking effect exerted by the tax.

The evolutionary algorithm we employ evaluates a set of equal-yield tax reforms involving all the 33 parameters of the tax; all these tax structures are able to better balance equity and efficiency as well as to control the re-ranking effect; by considering the situation observed before the tax reform, this methodology also allows the solutions to minimize the share of losing taxpayers. We obtain 187 different tax structures that are equally optimal for the problem under discussion. They range from solutions with low values for the redistributive effect and the average marginal tax rates to solutions with higher values for both these indicators, depending on the share of the losing taxpayers and the percentage deviation from the target tax revenue. 
Among these solutions, the government can choose the preferred one. As an example, here we discuss a solution that perfectly fit the target tax revenue and permit a very low share of losing taxpayers. With respect to the government reform, it is able to considerably reduce the average value of the effective marginal tax rates at the expenses of the redistributive effect, showing a trade-off between equity and efficiency for this problem.

\section{Acknowledgments}

We would like to thank Massimiliano Piacenza, Gilberto Turati and Achille Vernizzi for their useful comments that helped us improve the paper. Partial funding for this project was provided by the Natural Sciences and Engineering Council of Canada (NSERC) through its Discovery Grants program.

\section{References}

[1] K. Peter, S. Buttrick, D. Duncan, Global reform of personal income taxation, 1981-2005: Evidence from 189 countries, National Tax Journal 63 (3) (2010) $447-478$.

[2] B. Adhikari, J. Alm, Evaluating the economic effects of flat tax reforms using synthetic control methods, Southern Economic Journal 83 (2) (2016) 437-463.

[3] M. Reynolds, S. E., Public expenditures, taxes and the distribution of income: the United States, 1950, 1961,1970, New York Academic Press, 1977.

[4] E. Sanchez, G. Squillero, A. Tonda, Industrial Applications of Evolutionary Algorithms, Vol. 34 of Intelligent Systems Reference Library, Springer Berlin Heidelberg, Berlin, Heidelberg, 2012. doi :10.1007/978-3-642-27467-1.

[5] D. Bucur, G. Iacca, M. Gaudesi, G. Squillero, A. Tonda, Optimizing groups of colluding strong attackers in mobile urban communication networks with evolutionary algorithms, Applied Soft Computing Journal 40 (2016) 416-426. doi:10.1016/j.asoc.2015.11.024.

[6] I. Deplano, G. Squillero, A. Tonda, Anatomy of a portfolio optimizer under a limited budget constraint, Evolutionary Intelligence 9 (4). doi:10.1007/ s12065-016-0144-3.

[7] M. Morini, S. Pellegrino, Personal income tax reforms: A genetic algorithm approach, European Journal of Operational ResearchIn Press. doi:10.1016/ j.ejor.2016.07.059. 
[8] J. Mirrlees, S. Adam, T. Besley, R. Blundell, S. Bond, R. Chote, M. Gammie, P. Johnson, G. Myles, J. M. Poterba, Tax by design, Oxford University Press, 2011.

[9] J. S. Mill, Principles of political economy, Longmans Green, 1848.

[10] P. A. Samuelson, Foundation of economic analysis, Harvard University Press, 1947.

[11] N. Kakwani, Measurement of tax progressivity: an international comparison, Economic Journal 87 (345) (1976) 71-80.

[12] J. A. Mirrlees, An exploration in the theory of optimum income taxation, The Review of Economic Studies.

[13] E. Saez, Using elasticities to derive optimal income tax rates, The Review of Economic Studies 68 (1) (2001) 205-229. doi:10.1111/1467-937x.00166.

[14] R. Aaberge, U. Colombino, Using a microeconometric model of household labour supply to design optimal income taxes, The Scandinavian Journal of Economics 115 (2) (2013) 449-475. doi:10.1111/sjoe.12015.

[15] K. Roed, S. Strom, Progressive taxes and the labour market: is the tradeoff between equality and efficiency inevitable?, Journal of Economic Surveys 16 (1) (2002) 77-110. doi:10.1111/1467-6419.00160.

[16] Torben M. Andersen, Jonas Maibom, The big trade-off between efficiency and equity - is it there?, cepr discussion paper 11189, Tech. rep. (2016).

[17] M. Feldstein, Tax avoidance and the deadweight loss of the income tax, The Review of Economics and Statistics 81 (4) (1999) 674-680.

[18] J. Alm, S. M. Sheffrin, T. Dronyk-Trosper, What drives state tax reform, Public Finance Reviewdoi:10.1177/1091142116675028.

[19] C. Darwin, On the origin of species by means of natural selection. 1859, London: Murray Google Scholar.

[20] A. M. Turing, Computing machinery and intelligence, Mind (1950) 433-460.

[21] D. B. Fogel, Evolutionary computation: the fossil record, Wiley-IEEE Press, 1998.

[22] A. Eiben, J. Smith, Introduction to Evolutionary Computing, Springer Berlin Heidelberg, 2015. doi:10.1007/978-3-662-44874-8. 
[23] K. Deb, A. Pratap, S. Agarwal, T. Meyarivan, A fast and elitist multiobjective genetic algorithm: Nsga-ii, IEEE transactions on evolutionary computation 6 (2) (2002) 182-197.

[24] C. Gini, Sulla misura della concentrazione e della variabilità dei caratteri, Atti del Reale Istituto Veneto di Scienze, Lettere ed Arti 73 (2) (1914) 1203-1248.

[25] P. J. Lambert, The distribution and redistribution of income, Manchester University Press, 2001.

[26] S. Pellegrino, P. M., T. G., Developing a static microsimulation model for the analysis of housing taxation in italy, The International Journal of Microsimulation 4 (2) (2011) 73-85.

[27] S. Pellegrino, A. Vernizzi, On measuring violations of the progressive principle in income tax systems, Empirical Economics 45 (1) (2013) 239-245. doi: 10.1007/s00181-012-0613-1.

[28] M. G. Monti, S. Pellegrino, A. Vernizzi, On measuring inequity in taxation among groups of income units, Review of Income and Wealth 61 (1) (2015) 43-58. doi:10.1111/roiw. 12070.

[29] Bank of Italy, Household income and wealth in 2014, supplements to the statistical bulletin, year xxv (new series), no. 64., Tech. rep. (2015).

[30] Italian Department of Finance, Statistical reports, Tech. rep. (2016).

[31] Squillero, Giovanni, Tonda, Alberto, G. Squillero, A. P. Tonda, Divergence of character and premature convergence: A survey of methodologies for promoting diversity in evolutionary optimization, Information Sciences 329 (2016) 782-799. doi:10.1016/j.ins.2015.09.056.

URL http://porto.polito.it/2622368/, http://linkinghub.elsevier. com/retrieve/pii/S002002551500729X

[32] F. Herrera, M. Lozano, A. M. Sánchez, A taxonomy for the crossover operator for real-coded genetic algorithms: An experimental study, International Journal of Intelligent Systems 18 (3) (2003) 309-338.

[33] M. Takahashi, H. Kita, A crossover operator using independent component analysis for real-coded genetic algorithms, in: Evolutionary Computation, 2001. Proceedings of the 2001 Congress on, Vol. 1, IEEE, 2001, pp. 643-649. 
DEPARTMENT OF ECONOMICS AND STATISTICS

UNIVERSITY OF TORINO

Corso Unione Sovietica 218 bis - 10134 Torino (ITALY)

Web page: http://esomas.econ.unito.it/ 